\title{
Integrin-FAK signaling rapidly and potently promotes mitochondrial function through STAT3
}

Nishant P. Visavadiya ${ }^{\dagger}$, Matthew P. Keasey ${ }^{\dagger}$, Vladislav Razskazovskiy, Kalpita Banerjee, Cuihong Jia, Chiharu Lovins, Gary L. Wright and Theo Hagg ${ }^{*}$

\begin{abstract}
Background: STAT3 is increasingly becoming known for its non-transcriptional regulation of mitochondrial bioenergetic function upon activation of its S727 residue (S727-STAT3). Lengthy mitochondrial dysfunction can lead to cell death. We tested whether an integrin-FAK-STAT3 signaling pathway we recently discovered regulates mitochondrial function and cell survival, and treatments thereof.
\end{abstract}

Methods: Cultured mouse brain bEnd5 endothelial cells were treated with integrin, FAK or STAT3 inhibitors, FAK siRNA, as well as integrin and STAT3 activators. STAT3 null cells were transfected with mutant STAT3 plasmids. Outcome measures included oxygen consumption rate for mitochondrial bioenergetics, Western blotting for protein phosphorylation, mitochondrial membrane potential for mitochondrial integrity, ROS production, and cell counts.

Results: Vitronectin-dependent mitochondrial basal respiration, ATP production, and maximum reserve and respiratory capacities were suppressed within $4 \mathrm{~h}$ by RGD and av 33 integrin antagonist peptides. Conversely, integrin ligands vitronectin, laminin and fibronectin stimulated mitochondrial function. Pharmacological inhibition of FAK completely abolished mitochondrial function within $4 \mathrm{~h}$ while FAK siRNA treatments confirmed the specificity of FAK signaling. WT, but not S727A functionally dead mutant STAT3, rescued bioenergetics in cells made null for STAT3 using CRISPR-Cas9. STAT3 inhibition with stattic in whole cells rapidly reduced mitochondrial function and mitochondrial pS727-STAT3. Stattic treatment of isolated mitochondria did not reduce pS727 whereas more was detected upon phosphatase inhibition. This suggests that S727-STAT3 is activated in the cytoplasm and is short-lived upon translocation to the mitochondria. FAK inhibition reduced pS727-STAT3 within mitochondria and reduced mitochondrial function in a non-transcriptional manner, as shown by co-treatment with actinomycin. Treatment with the small molecule bryostatin-1 or hepatocyte growth factor (HGF), which indirectly activate S727-STAT3, preserved mitochondrial function during FAK inhibition, but failed in the presence of the STAT3 inhibitor. FAK inhibition induced loss of mitochondrial membrane potential, which was counteracted by bryostatin, and increased superoxide and hydrogen peroxide production. Bryostatin and HGF reduced the substantial cell death caused by FAK inhibition over a $24 \mathrm{~h}$ period.

Conclusion: These data suggest that extracellular matrix molecules promote STAT3-dependent mitochondrial function and cell survival through integrin-FAK signaling. We furthermore show a new treatment strategy for cell survival using S727-STAT3 activators.

Keywords: Bioenergetics, Cell death, CRISPR, ECM, Endothelial cell, Focal adhesion kinase, Integrin, Mitochondria, Vitronectin, STAT3

\footnotetext{
* Correspondence: haggt1@etsu.edu

'Equal contributors

Department of Biomedical Sciences, Quillen College of Medicine, East

Tennessee State University, Building 178, Maple Ave, PO Box 70582, Johnson

City, TN37614, USA
} 


\section{Background}

Integrins are heterodimer transmembrane receptors which bind ECM molecules to promote cell adhesion and initiate intracellular signaling that can lead to cell survival $[1,2]$. Disruption of integrin binding can cause cell death, especially for cells attached to basement membranes [3], e.g., endothelial cells in the central nervous system (CNS). Among others, endothelial cells express $\alpha v \beta 3$ integrins which contribute to their survival $[4,5]$. Integrin signaling is important for normal endothelial cell function in maintaining the blood-brain-barrier (BBB) [6, 7], whose disruption by neural injury and stroke leads to disease progression [8]. FAK is one of the major integrin signaling mediators and is activated via autophosphorylation on Y397 [9] which can suppress apoptosis in endothelial cells [10].

Mitochondria not only play a vital role in energy production, particularly in the CNS [11], but also have emerged as a key stress-signaling hub within the cell [12]. CNS endothelial cells have a very high mitochondrial mass compared to those of other organs [13], and mitochondrial function is important for maintaining the BBB and ATP-dependent trans-endothelial transport $[13,14]$. Mitochondrial dysfunction after neurological insults plays a role in BBB breakdown and tissue degeneration $[7,15,16]$. Lengthy mitochondrial bioenergetic dysfunction leads to depletion of ATP, increased production of reactive oxygen/nitrogen species, calcium dysregulation, and release of pro-apoptotic proteins, leading to cell death $[17,18]$.

Integrins can prevent apoptosis through FAK-AKT signaling $[10,19,20]$, and inhibiting mitochondria-associated bit1 [20, 21], but have not been implicated in bioenergetic function. We recently discovered an integrin signaling pathway that inhibits CNTF expression, involving FAK, JNK and the S727 residue of the transcription factor STAT3 [22]. Depending on phosphorylation of residues S727 or Y705, STAT3 can inhibit or promote nuclear gene expression [23]. Recent seminal studies identified a nontranscriptional role of pS727-STAT3 in stimulating mitochondrial bioenergetic function through electron transport chain (ETC) complex I, II and V activity [2426], probably not by binding directly [27], but by binding to prohibitin 1 [28]. STAT3 can also reduce formation of the mitochondrial permeability transition pore, possibly by interacting with cyclophilin D [29], thus maintaining membrane potential necessary for bioenergetic function, as well as preventing release of cytochrome-c, which leads to apoptosis [30]. STAT3 can also reduce ROS formation, possibly by improving complex I coupling, improving cell survival under ischemic conditions [30, 31]. It is unknown whether integrin or FAK signaling interacts with pS727STAT3 to regulate mitochondrial function.

A few studies have identified mechanisms that activate S727-STAT3, including cytoplasmic PKC isoforms [32, 33] and the c-Met receptor acting via ERK and AKT [34, 35]. The small molecule bryostatin 1 activates PKC [36] whereas HGF activates c-Met [34]. They are being developed for treating Alzheimer's disease [37] and spinal cord injury [38], respectively. Stimulating S727-STAT3 more directly may be a treatment strategy that can circumvent pathologically disrupted integrin or FAK signaling.

The present study determined whether ECM-integrinFAK-STAT3 signaling promotes mitochondrial function in cultured endothelial cells and whether treatments that activate STAT3 could rescue cells against the loss of FAK signaling.

\section{Methods}

\section{Cell culture}

The immortalized mouse brain endothelioma cell line (bEnd5) was created and characterized as a good model for CNS endothelial cells [39-41]. Culture medium components were from Gibco. The cells were grown in in T75 Flask (Cat \# CC7682-4175, CytoOne, Ocala, FL) in DMEM supplemented with $10 \%$ fetal calf serum, $3 \mathrm{mM}$ glutamine, 100 units $/ \mathrm{ml}$ penicillin and $100 \mu \mathrm{g} / \mathrm{ml}$ streptomycin, $1 \mathrm{mM}$ sodium pyruvate, $1 \%$ non-essential amino acids. Cells were passaged every seven days with cells up to 35 passages being used for experiments. Before use, replated cells were maintained for $24 \mathrm{~h}$ except where noted specifically. The cells were counted in high resolution images obtained with a $10 \times$ objective, five fields per well, using Image software (NIH), with 3-5 wells per condition.

\section{Mitochondrial bioenergetics measurements}

Mitochondrial bioenergetics measurements were made with an XF24 Extracellular Flux Analyzer (Seahorse Bioscience, North Billerica, MA). Cell density was optimized for recommended basal OCR ranges of 50-400 pMole/Min. For vitronectin (VTN) experiments, XF-24 culture plates were incubated with poly-d-lysine for $1 \mathrm{~h}$ (50 $\mathrm{\mu g} / \mathrm{ml}$; Sigma), washed $3 \times$ with autoclaved $\mathrm{H}_{2} \mathrm{O}$, dried and coated with recombinant human VTN (0.5 $\mathrm{\mu g} / \mathrm{cm}^{2}$, Cat\#SRP3186, Sigma) for $1 \mathrm{~h}$. BEnd5 cells were seeded at 100,000/well with or without RGDS (Arg-Gly-Asp-Ser peptide, $100 \mu \mathrm{g} / \mathrm{ml}$, Cat\#3498, Tocris, Bristol, UK) or P11 (His-Ser-Asp-Val-His-Lys- $\mathrm{NH}_{2}$ peptide, $10 \mu \mathrm{g} / \mathrm{ml}$, Cat\#4744, Tocris) peptides in serum-free medium supplemented with 2\% B27 (Gibco cat\# 10889038) for $4 \mathrm{~h}$. We also tested the effects of VTN, EHS mouse laminin-111 (Cat\#L2020, Sigma) and human plasma fibronectin (Cat\#F3879, Sigma) as $50 \mu \mathrm{g} / \mathrm{ml} \mathrm{sub-}$ strate with $10 \mu \mathrm{g} / \mathrm{ml}$ added to serum-free medium for $4 \mathrm{~h}$. For the other experiments, 50,000 bEnd5 cells/well were seeded without substrate and grown for $44 \mathrm{~h}$ before $4 \mathrm{~h}$ incubation with FAK14 (5 or $10 \mu \mathrm{M}$, Cat\#3414, Tocris) or stattic (5 or $10 \mu \mathrm{M}$, Cat\#2798, Tocris) with or 
without bryostatin (50 nM, Cat\#2383, Tocris) or HGF (500 ng/ml, Cat\#315-23, PeproTech, Rocky Hill, NJ) or actinomycin D $(0.3 \mu \mathrm{g} / \mathrm{ml}$, Cat\#1229, Tocris) treatment with or without $5 \mu \mathrm{M}$ FAK14. After treatments, cells were washed once with XF base media supplemented with $2.5 \mathrm{mM}$ glucose and $1 \mathrm{mM}$ sodium pyruvate, and incubated for $1 \mathrm{~h}$ in a non- $\mathrm{CO}_{2}$ incubator. Before use, sensor cartridges were hydrated, loaded with oligomycin (Cat\# 495455, Millipore), carbonyl cyanide 4-(trifluoromethoxy) phenylhydrazone (FCCP, Cat\# 0453, Tocris, $1 \mu \mathrm{M}$ as used by others [42, 43], antimycin A (Cat\# A8654, Sigma), and calibrated according to manufacturer's instructions. XF24 plates with cells were then loaded and mitochondrial respiration measurements performed according to a standard software protocol. The basal OCR, ATP production, maximum reserve and respiratory capacity were calculated as described [43], with averages calculated from five wells per condition in each individual experiment. Bioenergetics data are presented as a representative original trace (OCR raw data) while bar graphs were normalized to the average of controls for a set of experiments.

\section{CRISPR-Cas9 mediated knockdown of STAT3}

CRISPR-Cas9 pre-cloned guide RNA cassettes targeting mouse STAT3 were purchased from Origene (Cat\# KN316845) and knockdown performed according to [44] with some alterations. Briefly, $2 \times 10^{5}$ bEnd5 cells were seeded into 6 -well plates and maintained for $24 \mathrm{~h}$. Lipofectamine 3000 (Cat\# L3000, Invitrogen) was used at $0.5 \%$ complexed with $5 \mu \mathrm{g}$ plasmid $(2.5 \mu \mathrm{g}$ Cas9-gRNA with $2.5 \mu \mathrm{g}$ Donor) in Opti-MEM. Transfections were performed according to standard procedures, with cells maintained for $24 \mathrm{~h}$ after transfection. Transfection medium was removed from cells the following day and replaced with fresh medium containing $2 \mu \mathrm{g} / \mathrm{ml}$ puromycin (Cat\# A1113803) which caused 100\% cell death in non-transfected control cells after 4 days. Cells resistant to puromycin treatment were grown in fresh medium and maintained until confluent ( 7-14 days). PCR primers were designed against regions of the mouse STAT3 gene flanking the guide-RNA target sequence and were: Forward 5'-GGCCTTGACCTGTCTGTCAT -3' and reverse $5^{\prime}$-TGTGCAGAGATCTCACCAAGT -3 ' to generate an amplicon of 849 bp in a reaction with $100 \mathrm{ng}$ of genomic DNA extracted from cells with the DNeasy Blood and Tissue kit (Qiagenssa, USA, Cat\# 69506). PCR products were run on an agarose gel for purification and sequencing performed by the Molecular Core Facility at ETSU using the following primer 5'-GGCCTTGACCTGTCTGTCAT -3'. A point mutation was identified at the predicted Cas9-guide RNA cut site, resulting in a frame shift. Knockout of protein was confirmed by western blots.

\section{Subcellular fractionation}

Mitochondria were isolated as previously described [45]. Briefly, cells were homogenized in ice-cold isolation buffer $(215 \mathrm{mM}$ mannitol, $75 \mathrm{mM}$ sucrose, $0.1 \%$ bovine serum albumin, $20 \mathrm{mM}$ HEPES, $1 \mathrm{mM}$ EGTA; $\mathrm{pH}$ adjusted to 7.2 with $\mathrm{KOH}$ ), followed by centrifugation, twice at 1,300 $\mathrm{g}$ for $3 \mathrm{~min}$ to obtain nuclear pellets. The supernatant was centrifuged at $13,000 \mathrm{~g}$ for $10 \mathrm{~min}$ to obtain mitochondrial pellets. The last supernatant was collected as the cytosolic fraction. The cold and the EGTA in the isolation buffer ensure that proteins remain phosphorylated and intact. Moreover, we have found that addition of protease and phosphatase inhibitors (Cat\# P8340, Sigma), supplemented with $1 \mathrm{mM}$ sodium orthovanadate, does not reveal any differences. The purity of sub-cellular fractions was confirmed using Western blotting for fraction-specific markers. For another experiment, mitochondria were treated with stattic $(10 \mu \mathrm{M})$ or okadaic acid $(1 \mu \mathrm{M}$; Cat\# 5934 , Cell Signaling) for $2 \mathrm{~h}$ in $\mathrm{KCl}$-based respiration buffer $(125 \mathrm{mM}$ $\mathrm{KCl}, 2 \mathrm{mM} \mathrm{MgCl}, 2.5 \mathrm{mM} \mathrm{KH_{2 }} \mathrm{PO}_{4}, 20 \mathrm{mM}$ HEPES and $0.1 \%$ bovine serum albumin, $\mathrm{pH} 7.2$ ) containing oxidative substrates pyruvate $(5 \mathrm{mM})$ and malate $(2.5 \mathrm{mM})$ before protein extraction.

\section{Western blot analysis}

Protein from whole cells was extracted using 1\% RIPA lysis buffer (cat\# R0278, Sigma) with standard protease and phosphatase inhibitors (Cat\# P8340, Sigma). Proteins from subcellular fractions and whole cell lysate were separated by SDS-PAGE using Criterion 4-20\% Tris-HCl (10-250 kD) gels (Bio-Rad, Hercules, CA). After transfer to PVDF membranes, and after washing in TBST buffer containing $0.1 \%$ Tween 20 , and blocking in $5 \%$ milk in TBST, the primary antibodies were diluted in $5 \%$ milk in TBST and incubated at $4{ }^{\circ} \mathrm{C}$ for $18 \mathrm{~h}$. Primary antibodies against pyruvate dehydrogenase (PDH, 1:2,500, Cat\#3205), pS727-STAT3 (1:400, Cat\#9134), STAT3 (1:1,000, Cat\#12640), pY397-FAK (1:500, Cat\#3283), FAK (1:1,000, Cat\#3285), $\alpha$-tubulin (1:2,000, Cat\#2125) all from Cell Signaling Technology (Danvers, MA) and histone 3H3 (1:15,000, ab1791) and ATPase (1:5,000, ab14730) from Abcam (Cambridge, MA). After washing in TBST, the membranes were incubated in species- and isotype-specific HRP-conjugated secondary antibodies in TBST (1:2000, Cat\#7074, Cat\#7076, Cell Signaling). Chemiluminescence (ECL, Cat\# 34080, ThermoFisher) was used to reveal immunoreactive protein bands, detected by X-ray film or imaged on a Licor Odyssey FC (Lincoln, NE) for $10 \mathrm{~min}$.

\section{Quantitative capillary ProteinSimple westerns}

For one of the FAK inhibition experiments, quantitative analysis of protein expression was performed according 
to the ProteinSimple protocol guide with reagents of a kit (Cat\#, SM-W004 and DM-001, ProteinSimple), except where noted. Briefly, cell lysates were diluted to $0.2 \mu \mathrm{g} / \mu \mathrm{l}$ with $0.1 \times$ sample buffer supplemented with $1 \times$ fluorescent molecular weight markers and $40 \mathrm{mM}$ DTT for a $5 \mu \mathrm{l}$ reaction $(1 \mu \mathrm{g}$ protein/reaction). Samples were heated at $95{ }^{\circ} \mathrm{C}$ for 5 min before loading into 24 single designated wells of a pre-filled plate along with blocking reagent, primary antibodies (1:25, pS727-STAT3, 1:50, tSTAT3, or 1:500, $\alpha$-tubulin and ATPase) in antibody diluent, with pSTAT3 and tubulin/ATPase or STAT3 and tubulin/ATPase mixed together for detection within the same capillary), anti-rabbit HRP conjugated secondary antibody, luminol-peroxide mix to generate chemiluminescence and washing buffer. Plates were loaded into the automated ProteinSimple "Wes" for electrophoresis and fluorescence imaged in real time by a CCD camera for immunodetection in the capillary system at default settings: Electrophoresis, 375 volts, $25 \mathrm{~min}$; blocking, $5 \mathrm{~min}$; primary antibody, $30 \mathrm{~min}$; secondary antibody, $30 \mathrm{~min}$. Data was analyzed using Compass software (ProteinSimple) and expressed as peak intensity or synthetic bands. Quantification was performed by normalizing areas under protein peaks to $\alpha$-tubulin loading control.

\section{siRNA and STAT3 plasmid transfections}

SiRNAs against mouse FAK (Cat\# L-041099, Dharmacon) or a non-targeting negative control (Cat\# D001810-10, Dharmacon) were transfected into bEnd5 cells using lipofectamine-2000 (Cat \#11668, Invitrogen) $24 \mathrm{~h}$ after plating cells in Seahorse plates at 12,500 cells/ well, with $50 \mathrm{nM}$ siRNA and $0.5 \%$ Lipofectamine according to manufacturer's protocol. A second transfection was performed $24 \mathrm{~h}$ later ( $48 \mathrm{~h}$ after plating) due to FAK's long protein half-life [46] and bioenergetics assessed 5 days later. Transfection efficiency was $>80 \%$ as visualized by fluorescent microscopy using siGLO RNA (Cat \#D-001630-02, Dharmacon). Mutant S727A STAT3 expression plasmid was obtained from Addgene (Cat\# 8708) while wild type mouse STAT3 was PCR amplified from cDNA and directionally cloned into a pcDNA 3.1(+) expression vector using BamHI and EcoRI restriction sites. bEnd5 cells were transfected with $500 \mathrm{ng}$ plasmid per well using lipofectamine 3000 (Cat\# L3000, Invitrogen) and maintained for $24 \mathrm{~h}$ prior to Sea Horse analysis.

\section{TMRM measurements}

For confocal imaging, bEnd5 cells were seeded at $10^{5}$ cells/35 mm clear bottom culture dishes (P35G-1.5-14c, MarTek Corp, Ashland, MA). After 24 h, cells were treated with FAK14 (5 or $10 \mu \mathrm{M}$ ) for $4 \mathrm{~h}$, followed by 30 min incubation with $20 \mathrm{nM}$ tetramethylrhodamine methyl and ethylesters, which accumulate within active mitochondria in a potentiometric fashion (TMRM, Cat\#T668, Invitrogen) and $20 \mu \mathrm{M}$ Hoechst 33342 (Cat \# 62249, ThermoFisher Scientific) dyes. The cells were imaged for TMRM red fluorescence $(544 / 590 \mathrm{~nm})$ and nuclear Hoechst blue fluorescence $(460 / 490 \mathrm{~nm})$ using a Leica SP8 confocal microscope.

For spectrofluorometry, bEnd5 cells were grown for $24 \mathrm{~h}$ at 10,000/well in 96 wells (Cat\#3997, Corning) and treated with FAK14 for $4 \mathrm{~h}$. Afterwards, mitochondrial membrane potential was estimated by incubation with 25 nM TMRM and $300 \mathrm{nM}$ DAPI (Dilactate, Invitrogen), to normalize for the number of cells, for $30 \mathrm{~min}$ at $37{ }^{\circ} \mathrm{C}$. Fluorescence (TMRM: 544/590, DAPI 360/450 nm excitation/emission) was measured with a plate reader. $\mathrm{O}_{2}^{-}$ formation was measured by incubation in $10 \mu \mathrm{M} 2-, 7-$ dichlorodihydrofluorescein diacetate $\left(\mathrm{DCFH}_{2}-\mathrm{DA}\right.$, Cat\# D6883, Sigma) and $5 \mathrm{U} / \mathrm{ml}$ horseradish peroxidase (HRP, CatP8375, Sigma) as described before [45]. Oxidized DCF fluorescence $(485 / 520 \mathrm{~nm})$ was measured after $10 \mathrm{~min}$ at $37{ }^{\circ} \mathrm{C} . \mathrm{H}_{2} \mathrm{O}_{2}$ production was measured using $1 \mu \mathrm{M}$ Amplex Red (Cat\#A36006, Invitrogen) and $0.25 \mathrm{U} / \mathrm{ml}$ HRP at $30{ }^{\circ} \mathrm{C}$ as described [45]. Formation of fluorescent resorufin from Amplex Red was measured (530/590 nm).

\section{Statistical analyses}

Statistical analyses were performed with Students t-test for two samples or with a One Way Analysis of Variance (ANOVA) followed by a Bonferroni post-hoc test using GraphPad Software (La Jolla, CA). The number of experiments indicated in the text are independent experiments.

\section{Results}

\section{Integrin antagonists inhibit mitochondrial function}

BEnd5 endothelial cells were cultured for $4 \mathrm{~h}$ in serumfree conditions on VTN substrate to provide a ligand for integrins, especially $\alpha v \beta 3$ integrin present on endothelial cells. The tetrapeptide RGDS, which blocks RGD binding ligands [47], as well as the P11 peptide which blocks $\alpha v \beta 3$ integrin [48], substantially inhibited mitochondrial function (Fig. 1a), with significantly reduced ATP production, maximum reserve capacity and maximum respiratory capacity (Fig. 1b). The $4 \mathrm{~h}$ incubation with RGDS and P11 did not cause any obvious changes in cell number (Fig. 1c, d), or protein content (Fig. 1e), indicating that the effects were not due to cell detachment. Conversely, maximum reserve and respiratory capacity were stimulated when integrin agonists VTN, laminin or fibronectin were added directly to bEnd5 cell culture medium for $4 \mathrm{~h}$ under serum-free conditions (Fig. 1f).

\section{FAK inhibition causes mitochondrial dysfunction}

FAK inhibitor 14 (FAK14, also named Y15: 1,2,4,5-Benzenetetramine tetrahydrochloride, $\mathrm{MW}=284$ ) is a water- 


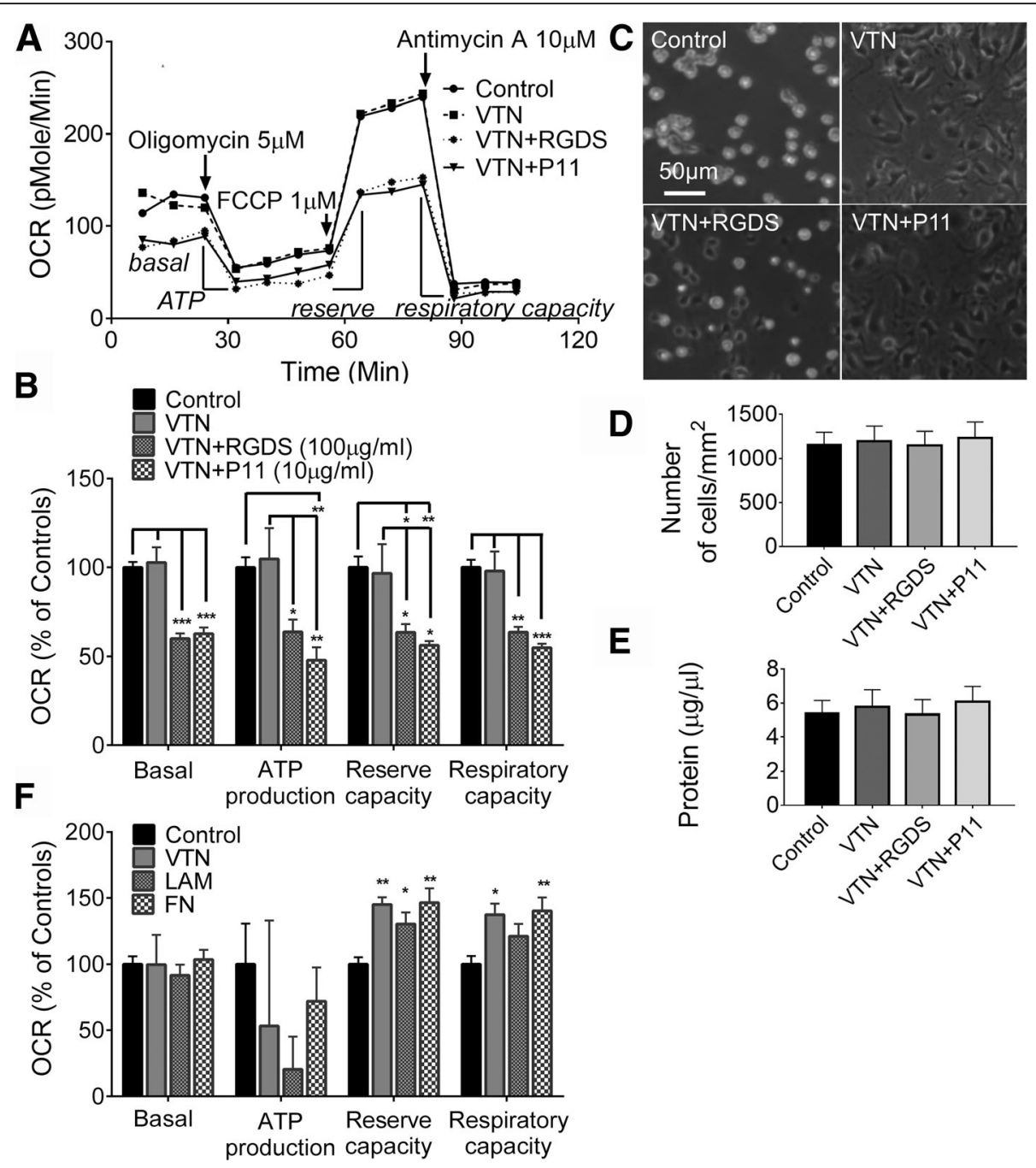

Fig. 1 RGD and av $\beta 3$ integrin blockade suppresses mitochondrial bioenergetics. a Traces from a representative experiment show mitochondrial bioenergetic deficits in mouse brain bEnd5 cells plated on vitronectin (VTN), in the presence of RGD integrin (RGDS) or av $\beta 3$ integrin (P11) blocking peptides, in serum free medium for $4 \mathrm{~h}$, as measured by oxygen consumption rate (OCR) in an XF24 Seahorse Flux Analyzer. Data are means of 5 wells per condition. $\mathbf{b}$ Integrin blockade reduced all four measures of cellular respiration relative to control (no VTN) and VTN treated cells. c Cells cultured in XF24 microplates for $4 \mathrm{~h}$ on no substrate or on VTN, with or without integrin blockade, seemed similar in number but cells without substrate and in the presence of RGDS were more rounded. The cell number (d) and protein content (e) in such cells, determined without subsequent Seahorse analyses, were not significantly different across all conditions. Cell counts were independently verified. $\mathbf{f}$ Cells cultured for $4 \mathrm{~h}$ with VTN, laminin (LAM) or fibronectin (FN) as substrate and added to serum-free media showed increased mitochondrial bioenergetics. All data are means \pm SEM of $3-4$ independent experiments. ${ }^{*} p<0.05,{ }^{* *} p<0.01$, and ${ }^{* * *} p<0.001$

soluble small-molecule FAK inhibitor that directly inhibits the essential Y397 autophosphorylation and thus, subsequent total phosphorylation and activation of FAK, with an IC50 of $1 \mu \mathrm{M}$ [49]. FAK14 has high specificity because it did not inhibit nine other recombinant kinases, importantly the Pyk2 homologue of FAK, as well as c-RAF, c-Src, EGFR, VEGFR-3, IGF-1, Met, PDGFR- $\alpha$, and PI3K, in an in vitro kinase assay [49]. FAK phosphorylation is greatly decreased already at $1 \mu \mathrm{M}$ in cultured cells [50]. FAK14 dose-dependently reduced mitochondrial function, affecting ATP production, maximum reserve capacity and maximum respiratory capacity of bEnd5 cells within $4 \mathrm{~h}$ (Fig. 2a, b). At $10 \mu \mathrm{M}$, FAK14 completely abolished mitochondrial bioenergetic function. FAK14 did not affect the number of cells or protein content when cells were incubated for $4 \mathrm{~h}$ in Seahorse microwells (without performing subsequent bioenergetics measurements; Fig. 2c, d). SiRNA knockdown of FAK (siFAK) in bEnd5 cells over a 5 day period (to account for the $>20$ h half-life of FAK [46], and confirmed by westerns for FAK, not shown) also led to mitochondrial dysfunction (Fig. 2e). The effect was not as large as seen with FAK14, perhaps because siRNA mediated knockdown of FAK reduced protein expression by $\sim 80 \%$ over the course of 

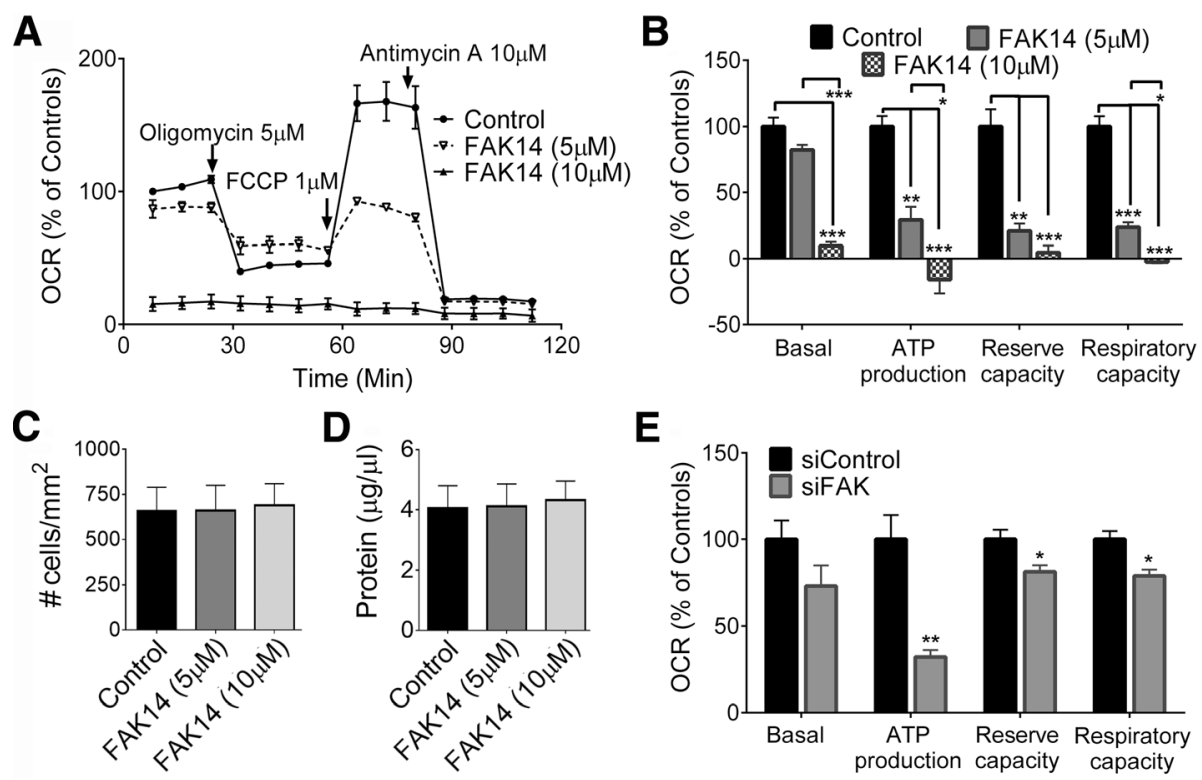

Fig. 2 FAK inhibition causes mitochondrial dysfunction. a Pharmacological inhibition of the integrin signaling molecule, FAK, with FAK14 treatment of bEnd5 cells for $4 \mathrm{~h}$ produced a robust and dose-dependent suppression of mitochondrial bioenergetic function as shown in a representative OCR trace. Cells were grown for $44 \mathrm{~h}$ without substrate before treatment. b FAK14 causes reductions in basal respiration, ATP production, and maximum reserve and respiratory capacity. The cell number $(\mathbf{c})$ and protein content $(\mathbf{d})$ were not different across conditions. Cell counts were independently verified. e SiRNA-mediated knockdown of FAK (siFAK) decreased ATP production, reserve capacity and respiratory capacity relative to a non-targeting siRNA control (siControl). Data are mean \pm SEM from 3 independent experiments. ${ }^{*} p<0.05,{ }^{* *} p<0.01,{ }^{* * *} p<0.001$, ns $=$ not significant versus control vehicle group

5 days, likely giving cells time to compensate to some extent as well as retaining a small amount of functional FAK. FAK14, as a small molecule inhibitor, would block all molecules with more or less immediate effect.

\section{S727-STAT3 inhibition causes mitochondrial dysfunction}

STAT3 was deleted in bEnd5 cells using the CRISPRCas9 method. Transfection of these cells with WT plasmids increased bioenergetic function whereas transfection with S727A mutants was without any effect (Fig. 3a). STAT3 protein deletion was confirmed by western blot (Fig. $3 \mathrm{~b}$ ) and the point mutation by sequencing (Fig. 3c). This shows that S727-STAT3 regulates mitochondrial function and is consistent with findings of others [24].

Stattic (6-nitrobenzo[b]thiophene 1,1-dioxide, MW = 211) is a small molecule inhibitor of STAT3, selectively blocking STAT3 SH2 domains at an IC50 of $5 \mu \mathrm{M}$, inhibiting STAT3 activation, dimerization and nuclear translocation [51]. It has high specificity against STAT3 compared to STAT1, and other transcription factors (cMyc, Max, Jun) and leads to reduced Y705 and S727 STAT3 (but not JAK1, JAK2, c-Src, AKT, JNK or ERK) phosphorylation $[29,51,52]$. Stattic caused mitochondrial dysfunction in bEnd5 cells as early as $2 \mathrm{~h}$ (Fig. 3d). Most of the pS727-STAT3 was present in the nucleus and mitochondria, as shown by sub-cellular fractionation
(Fig. 3e), consistent with other studies [24]. Stattic treatment of bEnd5 cells caused a reduction in mitochondrial pS727-STAT3 within $4 \mathrm{~h}$ (Fig. 3f).

To identify where S727-STAT3 is phosphorylated and dephosphorylated, freshly isolated bEND5 mitochondria were treated for $2 \mathrm{~h}$ with stattic or the serine/threonine phosphatase inhibitor, okadaic acid. Stattic did not have an effect, suggesting that STAT3 is phosphorylated in the cytoplasm before being imported, as others have found [53]. Okadaic acid increased pS727-STAT3 (Fig. 3g). A higher molecular weight pS727 band was visible after treatment with okadaic acid in a position where a faint band of total STAT3 could be seen after longer exposure (not shown).

\section{FAK inhibition reduces mitochondrial S727-STAT3}

FAK inhibitor FAK14 (Fig. 4a) caused a reduction in mitochondrial pS727-STAT3 after $4 \mathrm{~h}$. The higher molecular weight pS727-STAT3 could be detected in the freshly isolated mitochondria (Fig. 4a) and disappeared upon FAK inhibition with FAK14. The results were confirmed by a quantitative capillary western method, as shown in representative traces (Fig. $4 \mathrm{~b}$ ), which were converted with software to synthetic bands for presentation purposes (Fig. 4c), and quantified (Fig. 4d). Another FAK inhibitor, PF573228, also reduced pS727-STAT3, in concert with pFAK, as shown in whole cell lysates (Fig. 4e). 


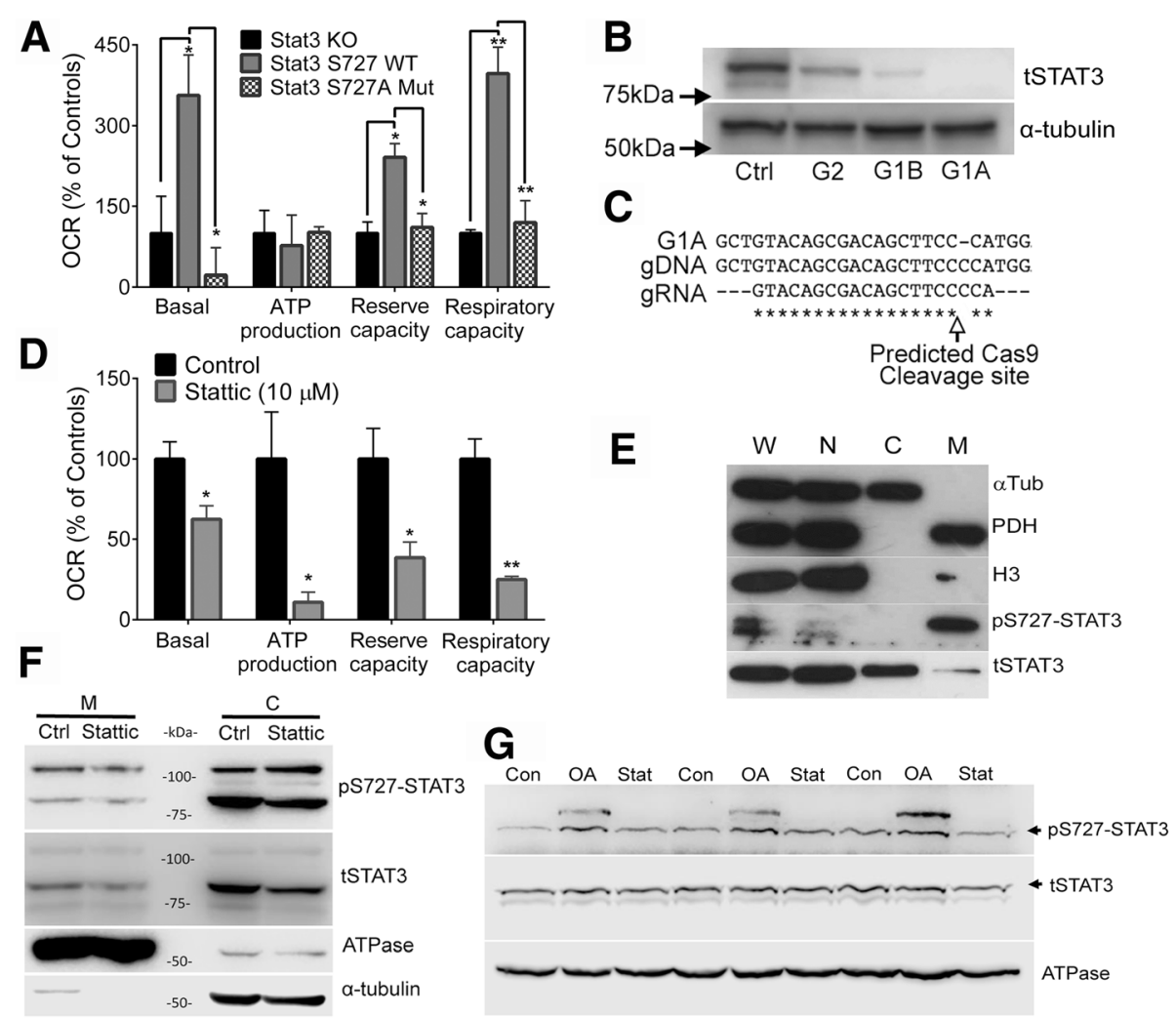

Fig. 3 S727-STAT3 inhibition causes mitochondrial dysfunction. a Expression plasmids for wildtype (WT), but not functionally dead S727A mutant, STAT3 increased bioenergetics function in bEnd5 cells rendered STAT3-/- by a CRISPR-Cas9 method. $N=3$. $\mathbf{b}$ Deletion of STAT3 protein was confirmed by western blot most clearly in cells transfected with the G1A guide RNA (G1A and G1B were replicate conditions of the same Cas9guideRNA plasmid) which was used for the bioenergetics experiment in (A). c DNA sequence data confirmed a point mutation and frame shift in exon 1. d Pharmacological inhibition of STAT3 with stattic for $2 \mathrm{~h}$ in bEnd5 cells reduced mitochondrial bioenergetic measures. $n=3$. e pS727STAT3 is predominantly present in the mitochondria and nucleus as shown in Western blots of protein extracts from sub-cellular fractions. Markers $=\mathrm{H} 3$ protein, nucleus $(\mathrm{N})$, a-tubulin, cytoplasm (C), PDH, mitochondria (M). W = whole cell lysate. tSTAT3 = total STAT3. $\mathbf{f}$ Cells treated for $4 \mathrm{~h}$ with the STAT3 inhibitor, stattic $(10 \mu \mathrm{M})$, had less PS727-STAT3 in their isolated mitochondria. The blot is representative of three experiments. g pS727-STAT3 was increased in isolated bEnd5 mitochondria treated with okadaic acid (OA: $1 \mu \mathrm{M})$ in respiration buffer, as detected by western blotting ( 3 independent experiments are shown). Stattic did not have any effect. A higher molecular weight band appeared after OA treatment in the pS727-STAT3 blot. A faint band could be seen in the same position after longer exposure of the total STAT3 blot (not shown)

Treatment with the transcription inhibitor, actinomycin, for $4 \mathrm{~h}$ did not significantly affect mitochondrial bioenergetics, nor the effects of FAK inhibition (Fig. 4f), consistent with the known non-transcriptional role of pS727-STAT3 [23]. The results so far suggest that integrin signaling through FAK promotes mitochondrial function by activating STAT3 on S727.

\section{S727-STAT3 activators rescue mitochondrial function and cells against $F A K$ inhibition}

Bryostatin-1 and HGF increase phosphorylation of S727STAT3 via PKC, and ERK activation, respectively [34, 54]. Here, both mitigated the reduced mitochondrial maximum reserve and respiratory capacity caused by a $4 \mathrm{~h}$ FAK14 treatment of bEnd5 cells (Fig. 5a). Further, FAK14 dose-dependently decreased pS727-STAT3, which was prevented by bryostatin and HGF (Fig. 5b). The substantial changes in pS727-STAT3 are likely not resulting from changes in cell survival (Fig. 6) because the total STAT3 and actin loading controls were similar. Bryostatin could not reduce mitochondrial dysfunction caused by stattic (Fig. 5c), evidence that its protective effects against FAK inhibition (Fig. 5a, and below) were mediated by STAT3 activation.

BEnd5 cell survival was assessed in regular tissue culture plates. FAK14 dose- and time-dependently caused loss of bEnd5 cells (Fig. 6a-e), up to more than 50\% (Fig. 6d, e), and may have reduced proliferation between 4 and 24 h (controls in Fig. 6b vs. c and d vs. e). No cell loss was observed in the bioenergetics experiments (Fig. 2), probably due to the different culture conditions. Bryostatin and HGF promoted bEnd5 cell survival caused by FAK14 treatment at both $4 \mathrm{~h}$ (Fig. 6a, b, d) and $24 \mathrm{~h}$ (Fig. 6c, e). 

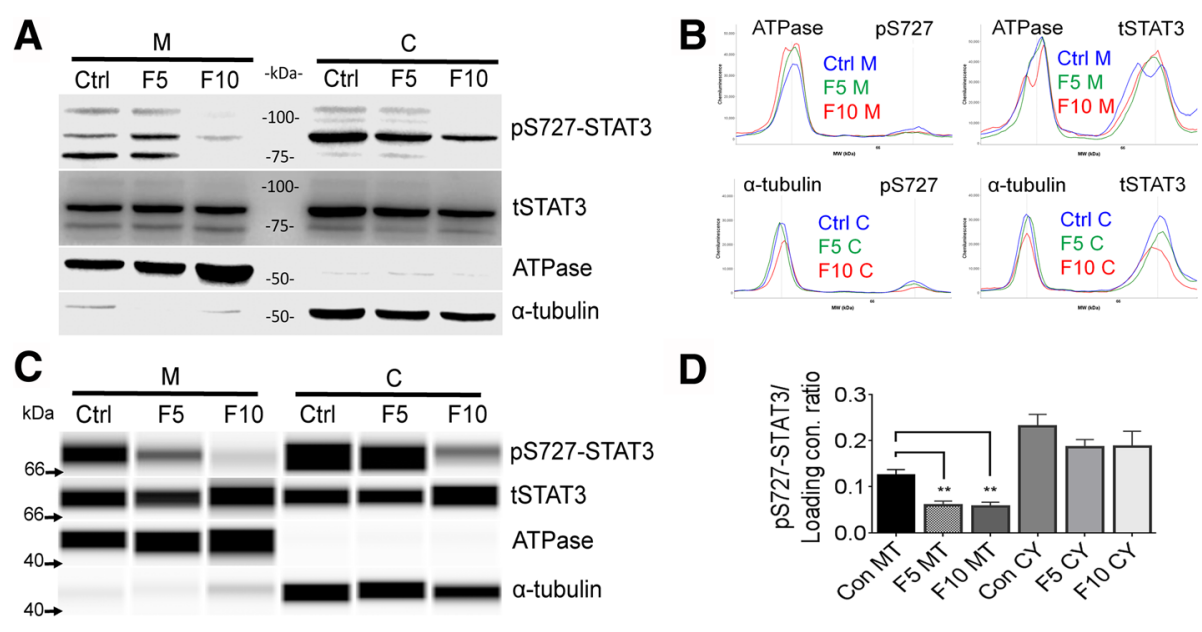

D

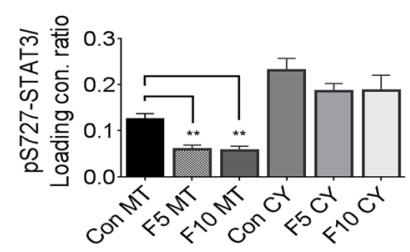

\section{E}

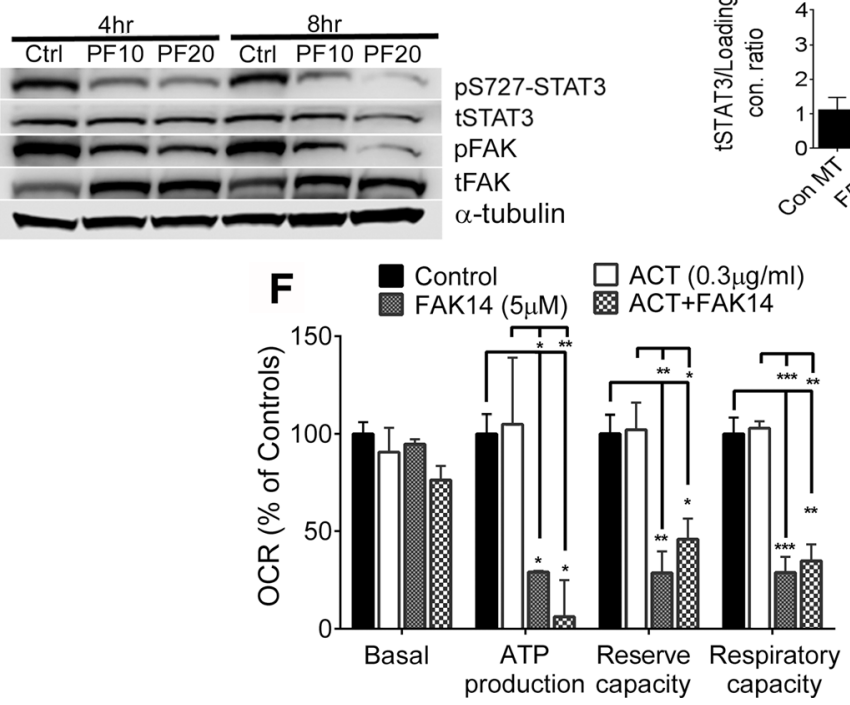

Fig. 4 FAK inhibits mitochondrial S727-STAT3 phosphorylation. a A 4 h FAK14 treatment of bEnd5 cells reduced pS727-STAT3 in both the mitochondrial and cytoplasmic fractions. Blots are representative for 5 experiments. $\mathbf{b}$ This reduction was confirmed by quantitative capillary western blotting with representative chemiluminescent spectrograms and synthetic bands (c). $\mathbf{d}$ Quantitation was performed of spectrograms confirmed a clear and significant decrease in pS727-STAT3 following $4 \mathrm{~h}$ FAK14 treatment in the mitochondrial fractions $(n=3)$. e Treatment with another more lipophilic FAK antagonist (PF573228: PF at 10 or $20 \mu \mathrm{M}$ ) for 4 or $8 \mathrm{~h}$ showed decreases in pS727-STAT3 in conjunction with decreased pFAK in whole cell lysates. $\mathbf{f}$ Incubation with the global transcriptional inhibitor actinomycin D $(0.3 \mu \mathrm{g} / \mathrm{ml}, 4 \mathrm{~h})$ did not significantly change mitochondrial bioenergetics under control or FAK14 conditions

\section{FAK inhibition causes mitochondrial depolarization and ROS production}

A normal mitochondrial membrane potential $\left(\Delta \Psi_{\mathrm{m}}\right)$ is essential for ATP generation [55]. FAK14 caused a dosedependent reduction in TMRM fluorescent signal, a measure of $\Delta \Psi \mathrm{m}$, in bEnd5 cells after $4 \mathrm{~h}$ as shown by confocal images (Fig. 7a) and spectrofluorometry of cell extracts (Fig. 7b). At $10 \mu \mathrm{M}$, FAK14 caused a complete loss of membrane potential to levels seen with the FCCP uncoupler of mitochondrial oxidative phosphorylation. Bryostatin increased mitochondrial polarization, as assessed with TMRM, in a dose-dependent manner in the presence of FAK14, but did not have an effect by itself (Fig. 7c). Mitochondrial failure can be induced by excessive ROS formation [56]. A $4 \mathrm{~h}$ treatment with FAK14 dose-dependently increased superoxide (Fig. 7d) and $\mathrm{H}_{2} \mathrm{O}_{2}$ (Fig. 7e) formation. Bryostatin did not affect this FAK14-induced ROS formation (data not shown).

\section{Discussion}

The present study demonstrates that ECM-integrinFAK signaling regulates mitochondrial bioenergetics via p5727-STAT3. This adds an important component to what was known about integrin signaling functions. ECM-integrin binding is important for cell adhesion and regulates actin organization, cell movement and cell cycle control [57]. Integrins can play an important role in cell survival, especially of cells that are attached to 

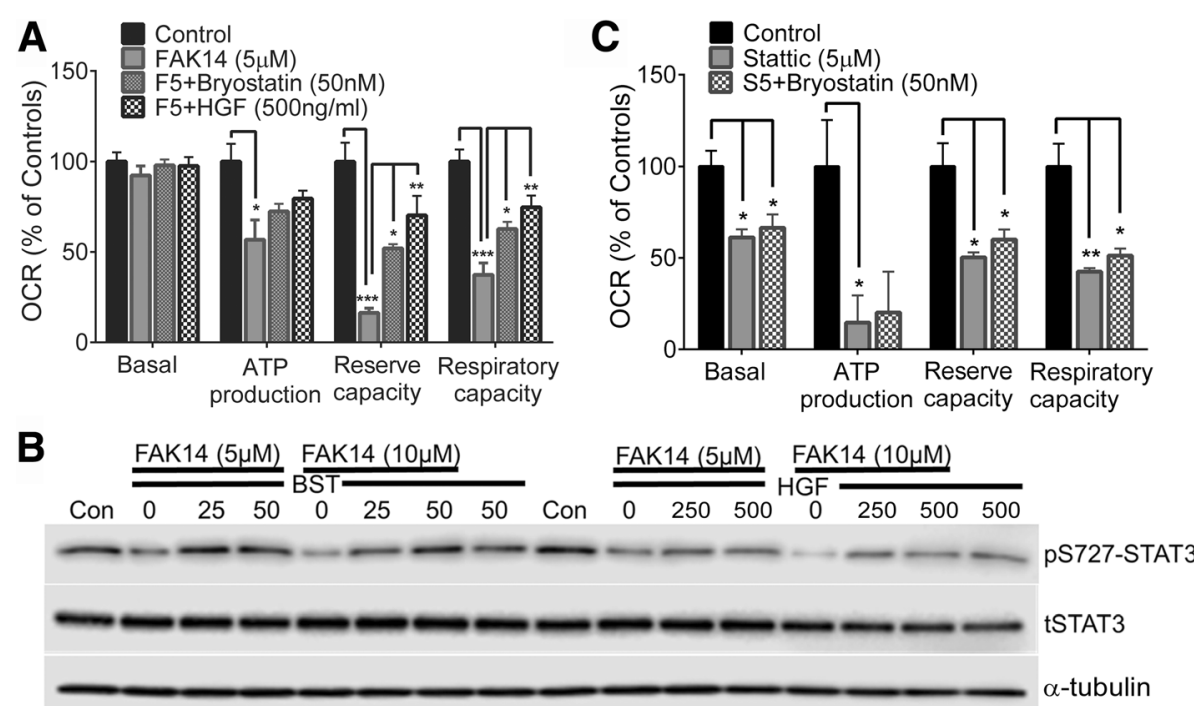

Fig. 5 pS727-STAT3 stimulation preserves mitochondrial bioenergetics against FAK inhibition. a Bryostatin and HGF preserved reserve and respiratory capacity in bEnd5 cells incubated with FAK14 (5 $\mu \mathrm{M}, \mathrm{F} 5)$ for $4 \mathrm{~h}$. Data are mean \pm SEM from 3 independent experiments. ${ }^{*} p<0.05$, ${ }^{* *} p$ $<0.01,{ }^{* *} p<0.001$. $\mathbf{b}$ Western blots of whole cell lysates showing that bryostatin (BST) and HGF preserve pS727-STAT3 in the presence of FAK14 (representative for 3 independent experiments). c Bryostatin does not affect the mitochondrial bioenergetics dysfunction caused by STAT3 inhibition with stattic. $N=3$

basement membranes, such as endothelial cells which undergo anoikis when attachment is disrupted [19]. Disrupted integrin signaling can induce apoptosis by activating the pro-apoptotic Bad and Bax or reducing anti-apoptotic Bcl-2 [3, 58]. RGDS peptide can trigger pro-apoptotic induction and activation of caspase 8 and 9 in human endothelial cells [59]. The P11 antagonist of $\alpha v \beta 3$ integrin can cause apoptosis of human umbilical vein endothelial cells by up-regulating p53 expression resulting in caspase activation [60]. Moreover, lengthy low bioenergetics leads to pathological mitochondrial pore formation and cytochrome-C release thus initiating apoptotic death [17, 18, 61]. Our data suggest that the integrin-FAK-STAT3 pathway is involved in suppressing such cell death
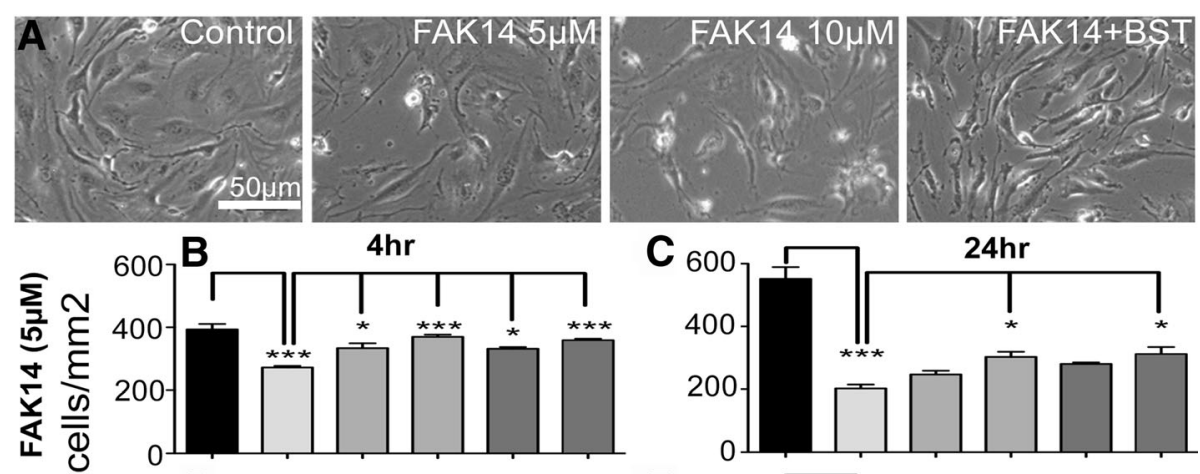

$24 \mathrm{hr}$
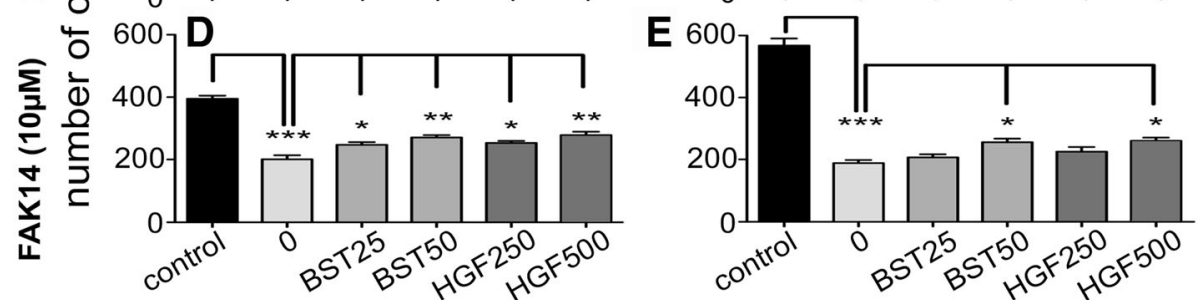

Fig. 6 Bryostatin and HGF reduce bEND5 cell death due to FAK inhibition. a Images are representative of bEnd5 cells grown for $4 \mathrm{~h}$ with $5 \mu \mathrm{M}$ FAK14 +/-bryostatin (BST) in regular tissue culture wells. b to e) Cell counts show that bryostatin and HGF can promote survival despite FAK inhibition with 5 or $10 \mu \mathrm{M}$ FAK14 for 4 or 24 h. Data are mean \pm SEM from 3 independent experiments. ${ }^{*} p<0.05,{ }^{* *} p<0.01$ and ${ }^{* * *} p<0.001$ 

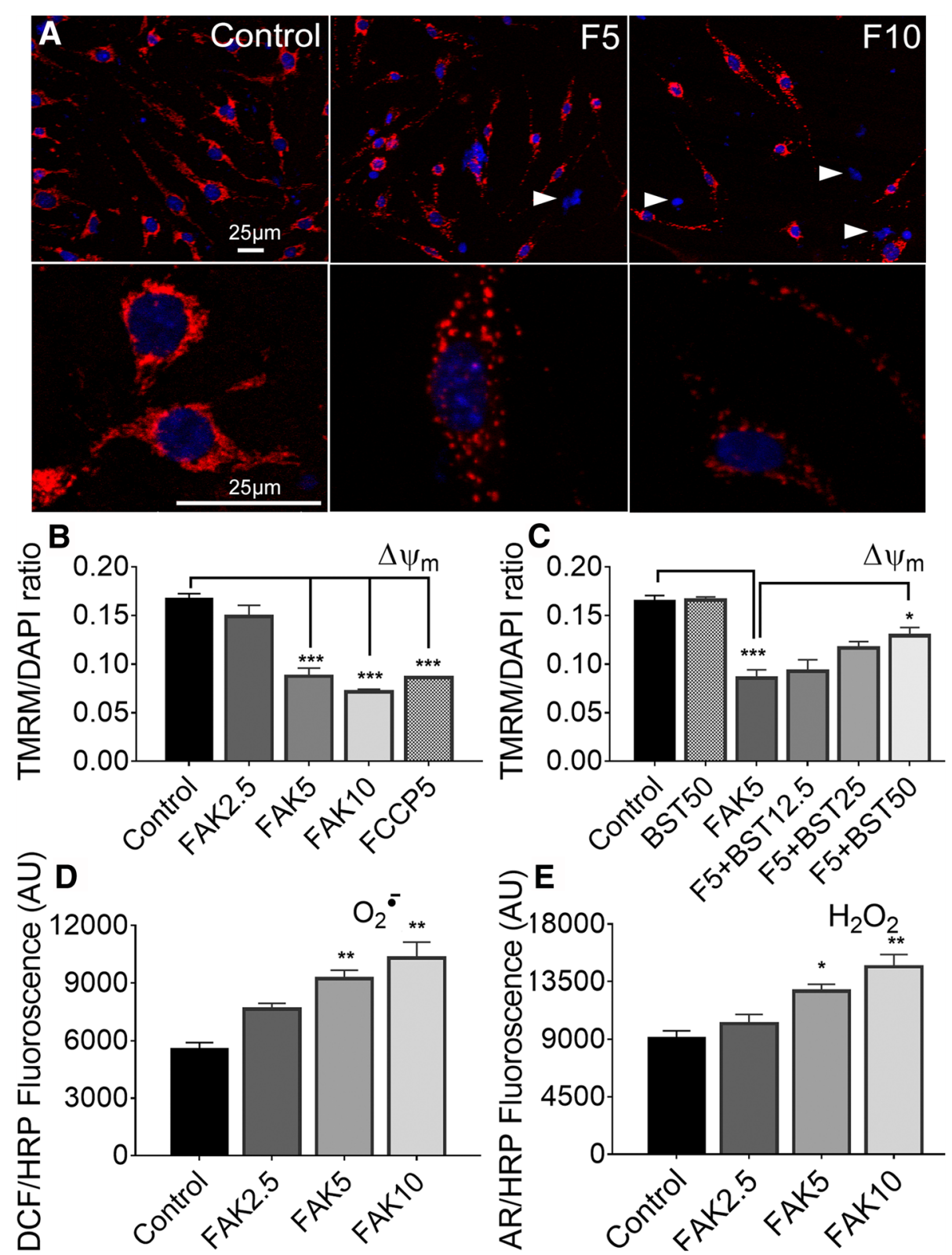

Fig. 7 FAK inhibition depresses mitochondrial membrane potential and increases ROS production. a FAK inhibition with FAK 14 for $4 \mathrm{~h}$ caused a dose-dependent reduction in mitochondrial membrane potential, as shown by confocal images of red TMRM fluorescence in bEnd5 cells. Cells with complete mitochondrial failure are indicated by arrowheads and detectable only by blue nuclear Hoechst staining. b Spectrometry of TMRM in extracts was used to quantify the effects, and shows that $10 \mu \mathrm{M}$ FAK14 (FAK10) reduced the membrane potential to the same level as FCCP. Values were normalized to nuclear DAPI staining to account for differences in cell numbers. Data are mean \pm SEM from 3 independent experiments. ${ }^{*} p<0.05,{ }^{* *} p<0.01,{ }^{* * *} p<0.001$. c Bryostatin (BST) dose-dependently preserved mitochondrial membrane potential in the presence of FAK14. $\mathrm{N}=3$. FAK14 dose-dependently induced formation of $\mathbf{d}$ ) superoxide $\left(\mathrm{O}_{2}^{-}\right)$and $\left.\mathbf{e}\right) \mathrm{H}_{2} \mathrm{O}_{2} \cdot \mathrm{N}=3$

mechanisms by maintaining mitochondrial function and integrity. This is consistent with the finding that fibronectin knockdown induces apoptosis in rat mesangial cells in a mitochondria-dependent manner, mainly as a result of cytochrome c release and downstream caspase- 3 and -9 activation [62]. Conversely, laminin and fibronectin protect pancreatic cancer cells from death by mechanisms involving the inhibition of both mitochondrial depolarization and caspase activity [63]. Previously, we have shown that an $\alpha v \beta 3$ agonist peptide can rescue endothelial cells after contusive spinal cord injury in adult mice [64].

Integrin-FAK signaling also can regulate mitochondrial biogenesis and morphology. FAK inactivation in cardiomyocytes causes structural abnormalities in mitochondria [65]. Moreover, FAK interacts with mitochondrial transcriptional cascades and enhances mechanical stress- 
induced mitochondrial biogenesis [66]. It remains to be determined how the FAK-STAT3 pathway affects biogenesis and morphology.

Most of our experiments were conducted with VTN as an integrin ligand. Its effects on mitochondrial function were mediated at least by $\alpha v \beta 3$ integrin as shown by the inhibitory effects of the P11 peptide. Fibronectin and laminin also had a stimulating effect, consistent with their role in promoting endothelial cell survival [3, 67, 68], whereas RGD inhibition reduced bioenergetic function. Other ECM molecules also utilize RGD integrins and it remains to be determined whether additional basement membrane or ECM molecules [69] are involved in regulating mitochondrial function. Vitronectin is present in the basement membrane but also at high concentrations in the blood [70, 71]. It will be interesting to determine the role of plasma VTN on mitochondrial function or whether integrin activation is predominantly ab-luminal, luminal, or both in the vasculature. FAK may be predominantly clustered with the VTN receptor on the ab-luminal side of endothelial cells, where they would make contact with the basement membrane [72]. If so, it is possible that pathological VTN leakage from the blood would promote survival of endothelial cells.

Our data suggest that FAK activates S727-STAT3. It remains to be determined which pathways downstream of FAK might be involved, but could include the serine kinases JNK1 [22] or ERK [73]. The latter is also activated by HGF [34]. The bryostatin results suggest that one or more of the PKC kinases can activate STAT3 even under reduced FAK signaling conditions. FAK can also be activated by growth factor receptors and Gprotein-linked receptors [74, 75] raising the possibility that they too could promote to mitochondrial function. The ECM may be involved in orchestrating these miscellaneous extracellular regulators. Our acute pharmacological approach with FAK14 and stattic showed a remarkably complete cessation of mitochondrial bioenergetic function within $4 \mathrm{~h}$. A mitochondrial role for STAT3 has been convincingly demonstrated with STAT3 S727A mutants suppressing bioenergetic function by $50-70 \%$ [24]. Our results, validate these findings by confirming that expression of STAT3 S727A mutants cannot increase bioenergetic function in STAT3 knockout cells using CRISPR-Cas9, whereas wild type STAT3 controls can. Other pathways that regulate STAT3 pS727 activation might also be involved under more physiological conditions. For example, CNTF can promote mitochondrial function through NFKB expression and activity in dorsal root ganglion neurons [76]. It remains to be determined whether this effect is fully transcriptiondependent or might also involve S727-STAT3 activation.

The mechanisms and roles of STAT3 within the mitochondria are not well-understood. Our results with actinomycin are consistent with the known nontranscriptional nature of the role of STAT3 in mitochondrial function [24, 26], and support a non-transcriptional effect of FAK inhibition on mitochondria. In an apparent contradiction, in keratinocytes, S727-STAT3 can repress transcription of mitochondrial ETC genes, but no functional measures were reported [77]. Our finding that pS727-STAT3 is mainly found in the mitochondrial and nuclear fractions, but less in the cytoplasm, is consistent with the findings that STAT3 translocates upon S727 phosphorylation in the cytoplasm [53]. Moreover, treatment of isolated mitochondria with stattic, known to reduce phosphorylation and translocation [51], did not reduce mitochondrial pS727-STAT3. This suggests that the effects of integrin or FAK inhibition are mediated by a reduced translocation to the mitochondria, which may be dependent on chaperones such as HSPs $[78,79]$. We also find for the first time that dephosphorylation of S727-STAT3 occurs within the mitochondria, as isolated mitochondria treated for $2 \mathrm{~h}$ with the serine/threonine phosphatase inhibitor, okadaic acid, had more pS727STAT3. The rapidity suggests that mitochondrial pS727STAT3 is short-lived and its constant import dependent on external stimuli which activate FAK signaling. This would represent a mechanism for rapid adjustments to cellular energy demands. Okadaic acid is known to inhibit PP2A (and PP1) which has been associated with pS727-STAT3 dephosphorylation in the cytoplasm [80]. PP2A has been found in mitochondria [81] and has been linked to mitochondrial bioenergetics by promoting mitochondrial division through Drp1 dephosphorylation [82].

We detected an $\sim 100 \mathrm{kDa}$ pS727-STAT3 in okadaic acid-treated or freshly isolated mitochondria. This form may also have been found in avian neurons upon CNTF stimulation, showing a similar short-lived nature and dependency on persistent signaling [83]. A higher molecular weight STAT3 can also be detected in Cos1 cells (Fig. 4 in [23] and splenocytes (Fig. 3 in [84]). Our results suggest that only a very minor fraction of mitochondrial STAT3 exists in this form and might be newly imported STAT3 which is post-translationally modified.

Mitochondrial STAT3 is thought to maintain optimal oxidative phosphorylation, by interacting with ETC complexes I, II, and V, and inhibiting formation of the mitochondrial permeability transition pore which would lead to loss of mitochondrial membrane potential [26, 29]. Our results suggest that liganddependent integrin-FAK activation of S727-STAT3 is an important mechanism which maintains a physiological mitochondrial function. Together, our data support the idea that the integrin-FAK signaling pathway, through STAT3, prevents the loss of mitochondrial membrane potential and decreased ATP synthesis, which are key mediators of mitochondrial 
dysfunction and subsequent triggers for release of pro-apoptotic factors and cell death [85].

Our results also suggest that this pathway promotes the potential antioxidant role of STAT3. In this scenario, STAT3 binds to complex I iron sulfur clusters with its cysteines being oxidized to serve as electron donors, thus reducing ROS generation [30, 31]. Indeed, STAT3 can reduce ROS formation in cardiomyocytes [30], preventing excessive ROS levels which can lead to cell death [56]. Integrins and ECM molecules have been found to reduce $[86,87]$ or promote $[88,89]$ ROS production. It will be interesting to test whether pS727-STAT3 is differentially regulated under those conditions or in those cells. Mitochondrial ROS are also involved in physiological processes, including proliferation, differentiation and migration [90]. It remains to be determined whether the integrin-STAT3 pathway plays a role in these physiological functions. Our finding that bryostatin did not reduce superoxide and $\mathrm{H}_{2} \mathrm{O}_{2}$ formation caused by FAK inhibition may explain why it was not fully effective in rescuing mitochondrial function or cell survival, despite restoring normal pS727-STAT3 levels. This raises the possibility that FAK can regulate mitochondrial function through other pathways.

Our study also explored a potential therapeutic strategy for endothelial cells with dysfunctional integrin signaling such as is seen after traumatic detachment, by circumventing integrin-FAK signaling through direct STAT3 activation. Our results are proof of principle that this can be achieved, also because we have seen similar decreases in bioenergetics, pS727-STAT3, and mitochondrial membrane potential after FAK inhibitor treatment in primary endothelial cells derived from adult mouse brain (Visavadiya et al., unpublished results). However, although it remains to be seen whether this therapeutic approach can be optimized and applied to animal models of disease. This is a reasonable expectation because bryostatin is being explored as a treatment for Alzheimer's disease [37] and HGF is in clinical trials for spinal cord injury [38]. This new therapeutic strategy could have implications for disorders where endothelial cells are disturbed, e.g., to maintain proper BBB integrity during neurological or other insults. FAK inhibitors are in clinical trials for solid tumors [91, 92] due to their inhibition of angiogenesis and cell adhesion [49, 93]. Our results suggest that mitochondrial dysfunction caused by such agents could also explain some of the effects. In apparent contrast to our proposed effects of FAK inhibition on bioenergetics function and ROS, mitochondrial ROS could trigger gastric cancer progression by stimulating cancer cell migration via the $\beta 5$-integrin induction [94]. Also, mitochondrial bioenergetic dysfunction caused by mitochondrial DNA mutations leads to increased motility and migration in cytoplasmic hybrid cells "cybrid cells" which harbor A3243T mutation in the leucine transfer RNA gene through a mechanism involving ECM molecules [95]. It remains to be determined whether the integrin-FAK-STAT3 pathway plays different roles in different cell types, and whether it is absent in cancer cells which defeat anoikis to metastasize.

\section{Conclusions}

In conclusion, our data suggest that integrin-FAK signaling maintains mitochondrial bioenergetic function by maintaining membrane potential and ETC function, thus reducing ROS formation, via pS727-STAT3. Further, we propose a treatment strategy that can circumvent dysfunction of integrin signaling which may help to develop new neuroprotective treatments. Our finding also provides a platform to investigate fundamental mechanisms of how ligand binding to integrins modulate physiological mitochondrial bioenergetic function in cells.

\section{Abbreviations}

ACT: Actinomycin D; AKT: v-Akt murine thymoma viral oncogene/protein kinase B (PKB); ANOVA: One way analysis of variance; ATP: Adenosine triphosphate; ATPase: Adenosine triphosphate synthase; BBB: Blood-brain barrier; Bcl-2: B-cell lymphoma 2; bEnd5: Mouse brain endothelioma cell line; bit1: Bcl-2 inhibitor of transcription; BST: Bryostatin; Cas9: CRISPR associated protein 9; CNS: Central nervous system; CNTF: Ciliary neurotrophic factor; CRISPR: Clustered regularly interspaced short palindromic repeats; DAPI: 4',6diamidino-2-phenylindole; $\mathrm{DCFH}_{2}$-DA: 2-,7-dichlorodihydrofluorescein diacetate; DMEM: Dulbecco's modified eagle medium;

DNA: Deoxyribonucleic acid; ECL: Enhanced chemiluminescence; ECM: Extracellular matrix; EGTA: Ethylene glycol-bis( $\beta$-aminoethyl ether)$\mathrm{N}, \mathrm{N}, \mathrm{N}^{\prime}, \mathrm{N}^{\prime}$-tetraacetic acid; ERK: Extracellular signal-regulated kinases; ETC: Electron transport chain; F10: FAK14 $(10 \mu \mathrm{M})$; F5: FAK14 $(5 \mu \mathrm{M})$; FAK: Focal adhesion kinase; FAK14: 1,2,4,5-Benzenetetramine tetrahydrochloride; FCCP: Carbonyl cyanide 4-(trifluoromethoxy) phenylhydrazone; FN: Fibronectin; $\mathrm{H}_{2} \mathrm{O}_{2}$ : Hydrogen peroxide; $\mathrm{H} 3$ : Histone $\mathrm{H} 3$; HEPES: 4-(2-hydroxyethyl)-1-piperazineethanesulfonic acid; HGF: Hepatocyte growth factor; HRP: Horseradish peroxidase; HSPs: Heat shock proteins; JNK: c-Jun N-terminal kinases; $\mathrm{KCl}$ : Potassium chloride; $\mathrm{KH}_{2} \mathrm{PO}_{4}$ : Potassium phosphate monobasic; $\mathrm{KOH}$ : Potassium hydroxide; LAM: Laminin; $\mathrm{MgCl}_{2}$ : Magnesium chloride; NFKB: Nuclear factor kappa $\mathrm{B}_{;} \mathrm{O}_{2}^{-}$: Superoxide; OA: Okadaic acid; OCR: Oxygen consumption rate; $\mathrm{PDH}$ : Pyruvate

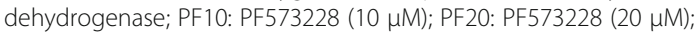
PF573228: 3,4-Dihydro-6-[[4-[[[3-(methylsulfonyl)phenyl]methyl]amino]-5(trifluoromethyl)-2-pyrimidinyl]amino]-2(1H)-quinolinon; PKC: Protein kinase C; pS727-STAT3: Phosphorylated serine 727 residue of STAT3;

PVDF: Polyvinylidene difluoride; pY397-FAK: Phosphorylated tyrosine 397 residue of FAK; RGD: Arg-Gly-Asp; RGDS: Arg-Gly-Asp-Ser;

RIPA: Radioimmunoprecipitation assay; RNA: Ribonucleic acid; ROS: Reactive oxygen species; S5: Stattic $(5 \mu M)$; S727-STAT3: Serine 727 residue of STAT3; SDS-PAGE: Sodium dodecyl sulfate-polyacrylamide gel electrophoresis; SiFAK: Small interfering RNA for FAK; siRNA: Small interfering RNA; STAT3: Signal transducer and activator of transcription 3; TBST: Tris-buffered saline tween 20; TMRM: Tetramethylrhodamine, methyl ester; tSTAT3: Total signal transducer and activator of transcription 3; VTN: Vitronectin; avß3: alpha $\vee$ beta $3 ; \Delta \psi_{m}$ : Membrane potential

\section{Acknowledgements}

We are grateful for the technical support by Aruna Visavadiya, Ying Li, and Rhesa Dykes.

\section{Funding}

This work was supported by NIH grant NS45734 and ETSU medical school funds. 


\section{Availability of data and materials}

All data generated or analyzed during this study are included in this published article.

\section{Author's contributions}

NPV, MPK, VR, KB, CL, CJ and TH performed experiments and analyzed and interpreted data. MPK and TH conceived the overall idea. NPV, MPK and TH wrote the paper. GLW provided intellectual input as well as technical guidance for the Seahorse experiments. All authors read and approved the manuscript.

\section{Authors' information}

Not applicable.

\section{Competing interests}

The authors declare that they have no competing interests.

\section{Consent for publication}

Not applicable.

\section{Ethics approval and consent to participate}

Not applicable.

\section{Received: 2 September 2016 Accepted: 6 December 2016} Published online: 15 December 2016

\section{References}

1. Giancotti FG, Ruoslahti E. Integrin signaling. Science. 1999;285:1028-32

2. Hynes RO. The extracellular matrix: not just pretty fibrils. Science. 2009;326: 1216-9.

3. Meredith JEJ, Schwartz MA. Integrins, adhesion and apoptosis. Trends Cell Biol. 1997;7:146-50.

4. Brooks PC, Montgomery AM, Rosenfeld M, Reisfeld RA, Hu T, Klier G, et al. Integrin alpha $\vee$ beta 3 antagonists promote tumor regression by inducing apoptosis of angiogenic blood vessels. Cell. 1994;79:1157-64.

5. Wang J, Milner R. Fibronectin promotes brain capillary endothelial cell survival and proliferation through alpha5beta1 and alphavbeta3 integrins via MAP kinase signalling. J Neurochem. 2006;96:148-59.

6. Del Zoppo GJ, Milner R. Integrin-matrix interactions in the cerebral microvasculature. Arterioscler Thromb Vasc Biol. 2006;26:1966-75.

7. Doll DN, Hu H, Sun J, Lewis SE, Simpkins JW, Ren X. Mitochondrial crisis in cerebrovascular endothelial cells opens the blood-brain barrier. Stroke. 2015; 46:1681-9.

8. Baeten KM, Akassoglou K. Extracellular matrix and matrix receptors in bloodbrain barrier formation and stroke. Dev Neurobiol. 2011;71:1018-39.

9. Toutant M, Costa A, Studler J-M, Kadaré G, Carnaud M, Girault J-A. Alternative splicing controls the mechanisms of FAK autophosphorylation. Mol Cell Biol. 2002:22:7731-43.

10. Frisch SM, Vuori K, Ruoslahti E, Chan-Hui PY. Control of adhesion-dependent cell survival by focal adhesion kinase. J Cell Biol. 1996;134:793-9.

11. de Castro IP, Martins LM, Tufi R. Mitochondrial quality control and neurological disease: an emerging connection. Expert Rev Mol Med. 2010;12:e12.

12. Harbauer AB, Zahedi RP, Sickmann A, Pfanner N, Meisinger C. The protein import machinery of mitochondria-a regulatory hub in metabolism, stress, and disease. Cell Metab. 2014;19:357-72.

13. Oldendorf WH, Cornford ME, Brown WJ. The large apparent work capability of the blood-brain barrier: a study of the mitochondrial content of capillary endothelial cells in brain and other tissues of the rat. Ann Neurol. 1977:1:409-17.

14. Grammas P, Martinez J, Miller B. Cerebral microvascular endothelium and the pathogenesis of neurodegenerative diseases. Expert Rev Mol Med. 2011;13:e19.

15. Sullivan PG, Rabchevsky AG, Waldmeier PC, Springer JE. Mitochondrial permeability transition in CNS trauma: cause or effect of neuronal cell death? J Neurosci Res. 2005;79:231-9.

16. Hall ED, Wang JA, Bosken JM, Singh IN. Lipid peroxidation in brain or spinal cord mitochondria after injury. J Bioenerg Biomembr. 2016;48:169-74.

17. Murphy AN, Fiskum G, Beal MF. Mitochondria in neurodegeneration: bioenergetic function in cell life and death. J Cereb Blood Flow Metab. 1999;19:231-45.

18. Mattson MP, Kroemer G. Mitochondria in cell death: novel targets for neuroprotection and cardioprotection. Trends Mol Med. 2003;9:196-205.
19. Ruoslahti E, Reed JC. Anchorage dependence, integrins, and apoptosis. Cell. 1994;77:477-8.

20. Lu Q, Rounds S. Focal adhesion kinase and endothelial cell apoptosis. Microvasc Res. 2012;83:56-63.

21. Jan Y, Matter M, Pai J-T, Chen Y-L, Pilch J, Komatsu M, et al. A mitochondrial protein, Bit1, mediates apoptosis regulated by integrins and Groucho/TLE corepressors. Cell. 2004;116:751-62.

22. Keasey MP, Kang SS, Lovins C, Hagg T. Inhibition of a novel specific neuroglial integrin signaling pathway increases STAT3-mediated CNTF expression. Cell Commun Signal. 2013;11:35.

23. Lim CP, Cao X. Serine phosphorylation and negative regulation of Stat3 by JNK. J Biol Chem. 1999;274:31055-61.

24. Wegrzyn J, Potla R, Chwae Y-J, Sepuri NBV, Zhang Q, Koeck T, et al. Function of mitochondrial Stat3 in cellular respiration. Science. 2009;323:793-7.

25. Boengler $K$, Ungefug $E$, Heusch G, Schulz R. The STAT3 inhibitor stattic impairs cardiomyocyte mitochondrial function through increased reactive oxygen species formation. Curr Pharm Des. 2013;19:6890-5.

26. Gough DJ, Corlett A, Schlessinger K, Wegrzyn J, Larner AC, Levy DE. Mitochondrial STAT3 supports Ras-dependent oncogenic transformation. Science. 2009;324:1713-6.

27. Phillips D, Reilley MJ, Aponte AM, Wang G, Boja E, Gucek M, et al. Stoichiometry of STAT3 and mitochondrial proteins: Implications for the regulation of oxidative phosphorylation by protein-protein interactions. J Biol Chem. 2010;285:23532-6.

28. Han J, Yu C, Souza RF, Theiss AL. Prohibitin 1 modulates mitochondrial function of Stat3. Cell Signal. 2014;26:2086-95.

29. Boengler K, Hilfiker-Kleiner D, Heusch G, Schulz R. Inhibition of permeability transition pore opening by mitochondrial STAT3 and its role in myocardial ischemia/reperfusion. Basic Res Cardiol. 2010;105:771-85.

30. Szczepanek K, Chen Q, Derecka M, Salloum FN, Zhang Q, Szelag M, et al. Mitochondrial-targeted Signal transducer and activator of transcription 3 (STAT3) protects against ischemia-induced changes in the electron transport chain and the generation of reactive oxygen species. J Biol Chem. 2011;286:29610-20.

31. Zhang Q, Raje V, Yakovlev VA, Yacoub A, Szczepanek K, Meier J, et al. Mitochondrial localized Stat3 promotes breast cancer growth via phosphorylation of serine 727. J Biol Chem. 2013:288:31280-8.

32. Xuan Y-T, Guo Y, Zhu Y, Wang O-L, Rokosh G, Messing RO, et al. Role of the protein kinase C-epsilon-Raf-1-MEK-1/2-p44/42 MAPK signaling cascade in the activation of signal transducers and activators of transcription 1 and 3 and induction of cyclooxygenase-2 after ischemic preconditioning. Circulation. 2005;112:1971-8.

33. Aziz MH, Manoharan HT, Sand JM, Verma AK. Protein kinase cepsilon interacts with Stat3 and regulates its activation that is essential for the development of skin cancer. Mol Carcinog. 2007;46:646-53.

34. Nakagami H, Morishita R, Yamamoto $K$, Taniyama $Y$, Aoki M, Matsumoto $K$, et al. Mitogenic and antiapoptotic actions of hepatocyte growth factor through ERK, STAT3, and AKT in endothelial cells. Hypertension. 2001;37:581-6.

35. Borowiak M, Garratt AN, Wustefeld T, Strehle M, Trautwein C, Birchmeier C. Met provides essential signals for liver regeneration. Proc Natl Acad Sci U S A. 2004;101:10608-13.

36. Kraft AS, Smith JB, Berkow RL. Bryostatin, an activator of the calcium phospholipid-dependent protein kinase, blocks phorbol ester-induced differentiation of human promyelocytic leukemia cells HL-60. Proc Natl Acad Sci U S A. 1986;83:1334-8.

37. Sun M-K, Nelson TJ, Alkon DL. Towards universal therapeutics for memory disorders. Trends Pharmacol Sci. 2015;36:384-94.

38. Sakai K, Aoki S, Matsumoto K. Hepatocyte growth factor and Met in drug discovery. J Biochem. 2015;157:271-84.

39. Steiner O, Coisne C, Engelhardt B, Lyck R. Comparison of immortalized bEnd5 and primary mouse brain microvascular endothelial cells as in vitro blood-brain barrier models for the study of T cell extravasation. J Cereb Blood Flow Metab. 2011;31:315-27.

40. Yang T, Roder KE, Abbruscato TJ. Evaluation of bEnd5 cell line as an in vitro model for the blood-brain barrier under normal and hypoxic/aglycemic conditions. J Pharm Sci. 2007:96:3196-213.

41. Wagner EF, Risau W. Oncogenes in the study of endothelial cell growth and differentiation. Semin Cancer Biol. 1994:5:137-45.

42. Shabalina IG, Jacobsson A, Cannon B, Nedergaard J. Native UCP1 displays simple competitive kinetics between the regulators purine nucleotides and fatty acids. J Biol Chem. 2004;279:38236-48. 
43. Dranka BP, Benavides GA, Diers AR, Giordano S, Zelickson BR, Reily C, et al. Assessing bioenergetic function in response to oxidative stress by metabolic profiling. Free Radic Biol Med. 2011;51:1621-35.

44. Keasey MP, Lemos RR, Hagg T, Oliveira JRM. Vitamin-D receptor agonist calcitrio reduces calcification in vitro through selective upregulation of SLC20A2 but not SLC20A1 or XPR1. Sci Rep. 2016;6:25802. Nature Publishing Group.

45. Visavadiya NP, Patel SP, VanRooyen JL, Sullivan PG, Rabchevsky AG. Cellular and subcellular oxidative stress parameters following severe spinal cord injury. Redox Biol. 2015;8:59-67.

46. Ochel HJ, Schulte TW, Nguyen P, Trepel J, Neckers L. The benzoquinone ansamycin geldanamycin stimulates proteolytic degradation of focal adhesion kinase. Mol Genet Metab. 1999;66:24-30.

47. Plow EF, Pierschbacher MD, Ruoslahti E, Marguerie GA, Ginsberg MH. The effect of Arg-Gly-Asp-containing peptides on fibrinogen and von Willebrand factor binding to platelets. Proc Natl Acad Sci U S A. 1985;82:8057-61.

48. Choi Y, Kim E, Lee Y, Han MH, Kang I-C. Site-specific inhibition of integrin alpha $\vee$ beta 3-vitronectin association by a ser-asp-val sequence through an Arg-Gly-Asp-binding site of the integrin. Proteomics. 2010;10:72-80.

49. Golubovskaya VM, Nyberg C, Zheng M, Kweh F, Magis A, Ostrov D, et al. A small molecule inhibitor, 1,2,4,5-benzenetetraamine tetrahydrochloride, targeting the y397 site of focal adhesion kinase decreases tumor growth. J Med Chem. 2008;51:7405-16.

50. Hochwald SN, Nyberg C, Zheng M, Zheng D, Wood C, Massoll NA, et al. A novel small molecule inhibitor of FAK decreases growth of human pancreatic cancer. Cell Cycle. 2009:8:2435-43.

51. Schust J, Sperl B, Hollis A, Mayer TU, Berg T. Stattic: a small-molecule inhibitor of STAT3 activation and dimerization. Chem Biol. 2006;13:1235-42.

52. Li C, Iness A, Yoon J, Grider JR, Murthy KS, Kellum JM, et al. Noncanonical STAT3 activation regulates excess TGF-beta1 and collagen I expression in muscle of stricturing Crohn's disease. J Immunol. 2015;194:3422-31.

53. Tammineni $P$, Anugula C, Mohammed F, Anjaneyulu M, Larner AC, Sepuri NBV. The import of the transcription factor STAT3 into mitochondria depends on GRIM-19, a component of the electron transport chain. J Biol Chem. 2013;288:4723-32.

54. Sud N, Kumar S, Wedgwood S, Black SM. Modulation of PKCdelta signaling alters the shear stress-mediated increases in endothelial nitric oxide synthase transcription: role of STAT3. Am J Physiol Lung Cell Mol Physiol. 2009;296:L519-26.

55. Dimroth P, Kaim G, Matthey U. Crucial role of the membrane potential for ATP synthesis by F(1)F(o) ATP synthases. J Exp Biol. 2000;203:51-9.

56. Orrenius S, Gogvadze V, Zhivotovsky B. Mitochondrial oxidative stress: implications for cell death. Annu Rev Pharmacol Toxicol. 2007;47:143-83.

57. Mahabeleshwar GH, Byzova TV. Vascular integrin signaling. Meth Enzymol. 2008:443:199-226.

58. Stupack DG, Cheresh DA. Get a ligand, get a life: integrins, signaling and cell survival. J Cell Sci. 2002;115:3729-38.

59. Aguzzi MS, Giampietri C, De Marchis F, Padula F, Gaeta R, Ragone G, et al. RGDS peptide induces caspase 8 and caspase 9 activation in human endothelial cells. Blood. 2004;103:4180-7.

60. Bang J-Y, Kim E-Y, Kang D-K, Chang S-I, Han MH, Baek K-H, et al. Pharmacoproteomic analysis of a novel cell-permeable peptide inhibitor of tumor-induced angiogenesis. Mol Cell Proteomics. 2011;10:M110.005264

61. Gogvadze V, Orrenius S, Zhivotovsky B. Multiple pathways of cytochrome c release from mitochondria in apoptosis. Biochim Biophys Acta. 2006;1757:639-47.

62. Wu D, Chen X, Guo D, Hong Q, Fu B, Ding R, et al. Knockdown of fibronectin induces mitochondria-dependent apoptosis in rat mesangial cells. J Am Soc Nephrol. 2005;16:646-57.

63. Vaquero EC, Edderkaoui M, Nam KJ, Gukovsky I, Pandol SJ, Gukovskaya AS. Extracellular matrix proteins protect pancreatic cancer cells from death via mitochondrial and nonmitochondrial pathways. Gastroenterology. 2003;125:1188-202.

64. Han S, Arnold SA, Sithu SD, Mahoney ET, Geralds JT, Tran P, et al. Rescuing vasculature with intravenous angiopoietin-1 and alphavbeta3 integrin peptide is protective after spinal cord injury. Brain. 2010;133:1026-42.

65. Peng X, Kraus MS, Wei H, Shen T-L, Pariaut R, Alcaraz A, et al. Inactivation of focal adhesion kinase in cardiomyocytes promotes eccentric cardiac hypertrophy and fibrosis in mice. J Clin Invest. 2006;116:217-27.

66. Tornatore TF, Dalla Costa AP, Clemente CFMZ, Judice C, Rocco SA, Calegari $V C$, et al. A role for focal adhesion kinase in cardiac mitochondrial biogenesis induced by mechanical stress. Am J Physiol Heart Circ Physiol. 2011;300:H902-12.
67. Isik FF, Gibran NS, Jang YC, Sandell L, Schwartz SM. Vitronectin decreases microvascular endothelial cell apoptosis. J Cell Physiol. 1998;175:149-55.

68. Davis GE, Senger DR. Endothelial extracellular matrix: biosynthesis, remodeling, and functions during vascular morphogenesis and neovessel stabilization. Circ Res. 2005;97:1093-107.

69. Naba A, Clauser KR, Ding H, Whittaker CA, Carr SA, Hynes RO. The extracellular matrix: tools and insights for the "omics" era. Matrix Biol. 2016;49:10-24.

70. Seiffert D, Schleef RR. Two functionally distinct pools of vitronectin (Vn) in the blood circulation: identification of a heparin-binding competent population of Vn within platelet alpha-granules. Blood. 1996;88:552-60.

71. Seiffert D, Keeton M, Eguchi Y, Sawdey M, Loskutoff DJ. Detection of vitronectin mRNA in tissues and cells of the mouse. Proc Natl Acad Sci U S A. 1991;88:9402-6.

72. Li S, Kim M, Hu YL, Jalali S, Schlaepfer DD, Hunter T, et al. Fluid shear stress activation of focal adhesion kinase. Linking to mitogen-activated protein kinases. J Biol Chem. 1997;272:30455-62.

73. Short SM, Talbott GA, Juliano RL. Integrin-mediated signaling events in human endothelial cells. Mol Biol Cell. 1998;9:1969-80.

74. Sieg DJ, Hauck CR, Ilić D, Klingbeil CK, Schaefer E, Damsky CH, et al. FAK integrates growth-factor and integrin signals to promote cell migration. Nat Cell Biol. 2000;2:249-56.

75. Streblow DN, Vomaske J, Smith P, Melnychuk R, Hall L, Pancheva D, et al. Human cytomegalovirus chemokine receptor US28-induced smooth muscle cell migration is mediated by focal adhesion kinase and Src. J Biol Chem. 2003;278:50456-65.

76. Saleh A, Roy Chowdhury SK, Smith DR, Balakrishnan S, Tessler L, Martens C, et al. Ciliary neurotrophic factor activates NF-KB to enhance mitochondrial bioenergetics and prevent neuropathy in sensory neurons of streptozotocininduced diabetic rodents. Neuropharmacology. 2013;65:65-73.

77. Macias E, Rao D, Carbajal S, Kiguchi K, DiGiovanni J. Stat3 binds to mtDNA and regulates mitochondrial gene expression in keratinocytes. J Invest Dermatol. 2014;134:1971-80.

78. Young JC, Hoogenraad NJ, Hartl FU. Molecular chaperones Hsp90 and Hsp70 deliver preproteins to the mitochondrial import receptor Tom70. Cell. 2003;112:41-50.

79. D'Silva P, Liu Q, Walter W, Craig EA. Regulated interactions of mtHsp70 with Tim44 at the translocon in the mitochondrial inner membrane. Nat Struct Mol Biol. 2004;11:1084-91.

80. Woetmann A, Nielsen M, Christensen ST, Brockdorff J, Kaltoft K, Engel AM, et al. Inhibition of protein phosphatase $2 \mathrm{~A}$ induces serine/threonine phosphorylation, subcellular redistribution, and functional inhibition of STAT3. Proc Natl Acad Sci U S A. 1999;96:10620-5.

81. Floyd BJ, Wilkerson EM, Veling MT, Minogue CE, Xia C, Beebe ET, et al. Mitochondrial protein interaction mapping identifies regulators of respiratory chain function. Mol Cell. 2016;63:621-32.

82. Dickey AS, Strack S. PKA/AKAP1 and PP2A/Bbeta2 regulate neuronal morphogenesis via Drp1 phosphorylation and mitochondrial bioenergetics. J Neurosci. 2011;31:15716-26.

83. Wishingrad MA, Koshlukova S, Halvorsen SW. Ciliary neurotrophic factor stimulates the phosphorylation of two forms of STAT3 in chick ciliary ganglion neurons. J Biol Chem. 1997;272:19752-7.

84. Haq R, Halupa A, Beattie BK, Mason JM, Zanke BW, Barber DL. Regulation of erythropoietin-induced STAT serine phosphorylation by distinct mitogenactivated protein kinases. J Biol Chem. 2002;277:17359-66.

85. Wang C, Youle RJ. The role of mitochondria in apoptosis*. Annu Rev Genet. 2009:43:95-118

86. Chen X, Abair TD, Ibanez MR, Su Y, Frey MR, Dise RS, et al. Integrin alpha1beta1 controls reactive oxygen species synthesis by negatively regulating epidermal growth factor receptor-mediated Rac activation. Mol Cell Biol. 2007;27:3313-26.

87. Roggia MF, Ueta T. alphavbeta5 integrin/FAK/PGC-1alpha pathway confers protective effects on retinal pigment epithelium. PLOS ONE. 2015;10:e0134870.

88. Kheradmand F, Werner E, Tremble P, Symons M, Werb Z. Role of Rac1 and oxygen radicals in collagenase-1 expression induced by cell shape change. Science. 1998;280:898-902.

89. Taddei ML, Parri M, Mello T, Catalano A, Levine AD, Raugei G, et al. Integrinmediated cell adhesion and spreading engage different sources of reactive oxygen species. Antioxid Redox Signal. 2007;9:469-81.

90. Poli G, Leonarduzzi G, Biasi F, Chiarpotto E. Oxidative stress and cell signalling. Curr Med Chem. 2004;11:1163-82.

91. Infante JR, Camidge DR, Mileshkin LR, Chen EX, Hicks RJ, Rischin D, et al. Safety, pharmacokinetic, and pharmacodynamic phase I dose-escalation trial 
of PF-00562271, an inhibitor of focal adhesion kinase, in advanced solid tumors. J Clin Oncol. 2012;30:1527-33.

92. Jones SF, Siu LL, Bendell JC, Cleary JM, Razak ARA, Infante JR, et al. A phase I study of VS-6063, a second-generation focal adhesion kinase inhibitor, in patients with advanced solid tumors. Invest New Drugs. 2015;33:1100-7.

93. Cabrita MA, Jones LM, Quizi JL, Sabourin LA, McKay BC, Addison CL. Focal adhesion kinase inhibitors are potent anti-angiogenic agents. Mol Oncol. 2011;5:517-26.

94. Hung W-Y, Huang K-H, Wu C-W, Chi C-W, Kao H-L, Li AF-Y, et al. Mitochondrial dysfunction promotes cell migration via reactive oxygen species-enhanced beta5-integrin expression in human gastric cancer SC-M1 cells. Biochim Biophys Acta. 1820;2012:1102-10.

95. Nunes JB, Peixoto J, Soares P, Maximo V, Carvalho S, Pinho SS, et al. OXPHOS dysfunction regulates integrin-beta1 modifications and enhances cell motility and migration. Hum Mol Genet. 2015;24:1977-90.

Submit your next manuscript to BioMed Central and we will help you at every step:

- We accept pre-submission inquiries

- Our selector tool helps you to find the most relevant journal

- We provide round the clock customer support

- Convenient online submission

- Thorough peer review

- Inclusion in PubMed and all major indexing services

- Maximum visibility for your research

Submit your manuscript at www.biomedcentral.com/submit
Biomed Central 